\title{
Educação em Direitos Humanos: uma proposta da Universidade Federal do Paraná (UFPR) à comunidade
}

\section{Human Rights Education: one proposition of the Federal University of Paraná (UFPR) to the community}

\author{
Silvia Helena Soares Schwab \\ Maria Tarcisa Silva Bega*
}

\begin{abstract}
RESUMO
A educação em Direitos Humanos, nos diversos níveis da educação formal e não formal, constitui-se num campo aberto a todas as iniciativas multiplicadoras que provoquem mudança comportamental e das relações sociais, de forma a construir cidadãos mais conscientes, capazes de mudar uma realidade extremamente perversa de tolerância com relação a práticas usuais nas sociedades. Este trabalho mostra experiência piloto realizada na UFPR e suas possibilidades de aplicação.
\end{abstract}

Palavras-chave: Educação; Direitos Humanos; experiência-piloto; metodologia.

\begin{abstract}
The Human Rights education in several formal and no formal education levels constitutes an open field to all multiplying initiatives which cause behavior and social relationship changes, as a way to construct more conscientious citizens, able to change an extremely perverse tolerance reality in relation to usual practices in societies. This work is a pilot experience performed at the UFPR and its application possibilities.
\end{abstract}

Keywords: Education; Human Rights; pilot-experience; methodology.

\section{RESUMEN}

La educación en Derechos Humanos, en los distintos niveles de educación formal y no formal, se constituye en un campo abierto a todas las iniciativas multiplicadoras, que provoquen cambio de comportamiento y de las relaciones sociales, de forma de construir ciudadanos más conscientes y capaces de cambiar una realidad extremadamente perversa de tolerancia con relación a prácticas usuales en las sociedades. Este trabajo muestra una experiencia piloto desarrollada en la UFPR y sus posibilidades de aplicación.

Palabras-clave: Educación; Derechos Humanos; experiencia-piloto; metodología.

Introdução

A relação entre processos sociais, formação cidadã e a questão de Direitos Humanos constitui uma ampla área de pesquisa, de discussão e construção de proposições. Neste contexto, a universidade como entidade formadora tem papel fundamental, uma vez que suas ações emanam da sociedade e nela se refletem. Como ponto inicial da reflexão e avaliação sobre a necessidade de educar

* Doutora, UFPR, Departamento de Física. silviass@ufpr.br.

** Doutora, UFPR, Departamento de Ciências Sociais. tarcisa@ufpr.br. 
em direitos humanos, analisa-se a questão da legitimação do desrespeito aos Direitos Humanos tendo em vista uma situação de descontrole social, a da violência no Brasil. Em recente reportagem da revista Veja sobre o filme Tropa de Elite (Brasil, 2007, direção José Padilha), destaca-se um parágrafo em que esta legitimação é expressa:

Na pesquisa encomendada por VEJA, chama atenção o fato de $51 \%$ dos espectadores desaprovarem a tortura como um meio de extrair confissões de criminosos. É uma maioria pequena - $47 \%$ aprovam esse método desumano -, mas que aponta no sentido da civilização. Seria até de esperar que o desespero dos brasileiros em relação à segurança se traduzisse numa proporção ainda mais larga de pessoas adeptas da tortura policial. ${ }^{1}$

Neste trecho, evidencia-se a legitimação da violência policial sob a motivação real da violência a qual é submetida a sociedade brasileira, num reflexo de um possível descontrole do Estado sobre o assunto. Neste contexto, e de forma geral, a questão que surge é qual o papel da educação em Direitos Humanos e de que forma ela pode ser realizada. Como afirma Benevides (2000):

A Educação em Direitos Humanos parte de três pontos essenciais: primeiro, é uma educação de natureza permanente, continuada e global. Segundo, é uma educação necessariamente voltada para a mudança, e terceiro, é uma inculcação de valores, para atingir corações e mentes e não apenas instrução, meramente transmissora de conhecimentos. Acrescente-se, ainda, e não menos importante, que ou esta educação é compartilhada por aqueles que estão envolvidos no processo educacional - os educadores e os educandos - ou ela não será educação e muito menos educação em direitos humanos. Tais pontos são premissas: a educação continuada, a educação para a mudança $e$ a educação compreensiva, no sentido de ser compartilhada e de atingir tanto a razão quanto a emoção ${ }^{2}$.

A conjugação entre os dois pensamentos evidencia o contraste e a dificuldade de educar em direitos humanos numa sociedade que se defronta com a complexidade das questões sociais e suas conseqüências. A questão que surge é como se vai realizar esse processo com membros de uma sociedade que estão sujeitos a todo tipo de influências e que, em conseqüencia destas, podem legitimar ações na contramão do que se quer ensinar e sensibilizar como função exatamente de suas especificidades.

Este artigo apresenta uma experiênciapiloto desenvolvida a partir de uma metodologia de trabalho que permite educar em Direitos Humanos, a partir da ação compartilhada de professores e alunos, com base em situações geradas em cada ambiente social e apresenta suas possibilidades de aplicação, via extensão universitária. Seu objetivo é contribuir para que, a partir de ações educativas, se fortaleça o processo de construção do cidadão consciente, capaz de agir e reagir na busca da solução dos problemas, cobrando respostas do Estado, da própria sociedade e de si mesmo, no fortalecimento de relações sociais respeitosas e igualitárias.

\footnotetext{
1 A reportagem, intitulada "A realidade, só a realidade" (CARNEIRO, 2007), foi retirada de: <http://veja.abril.com.br/171007/ p_080.shtml>.

${ }_{2}$ BENEVIDES, Maria Victória. Educação em Direitos Humanos: de que se trata? 2000. Disponível em: <http://www.hottopos.com/ convenit6/victoria.htm>.
} 


\section{Uma experiência-piloto na UFPR}

Histórico

No mês de maio de 2004, em Curitiba, através do Conselho de Reitores da Associação de Universidades Grupo Montevideo (AUGM) (http://www.grupomontevideo.edu.uy), e do Alto Comissariado das Nações Unidas para Refugiados (ACNUR) (http://www.acnur.org/), foi firmado um acordo marco no sentido de criar um Programa de Educação em Direitos Humanos e Direito Internacional dos Refugiados a se desenvolver em nível da Educação Superior. A finalidade foi ampliar o espectro de ação da ACNUR, vinculando e sistematizando o trabalho nas Universidades do Grupo, através da Cátedra ACNUR Sérgio Vieira de Mello (http: //www.universidad.edu.uy/ddhh/). No âmbito da UFPR, o programa foi também vinculado à Cátedra UNESCO de Cultura de Paz (AUGMUFPR). Tinha por objetivo apoiar o movimento de promoção, difusão, capacitação e investigação na matéria de Direitos Humanos nas áreas de: Direito Internacional dos Direitos Humanos, Direito dos Refugiados, Direito Internacional Humanitário, Direito dos Migrantes e Gênero, a partir de um enfoque interdisciplinar como eixo transversal. A implementação executouse através da constituição de um comitê coordenador, composto pelos professores: Carlos Roberto Soares (Geologia, Centro de Estudos do Mar), Ciméa Barbatto Bevilaqua (Antropologia, Ciências Humanas, Letras e Artes), Enilze Maria Ribeiro (Genética, Ciências Biológicas), José Antonio Peres Gediel (Direito, Ciências Jurídicas), Maria Tarcisa Silva Bega (Ciências Sociais, Ciências Humanas, Letras e Artes), Olga Lucia C. Firkowsky (Geografia, Ciências da Terra), Paulo Chiesa (Arquitetura e Urbanismo, Tecnologia), Pedro Rodolfo Bodê de Morais (Ciências Sociais, Ciências Humanas, Letras e Artes) e Sílvia Helena Soares Schwab
(Física, Ciências Exatas). Estes docentes, de diferentes áreas, agregaram esforços para a criação de uma disciplina semestral regular da UFPR, de caráter transversal, denominada Teoria e Prática em Direitos Humanos (HC 310), com carga horária de 60 horas e organizacionalmente ligada ao Departamento de Ciências Sociais, Setor de Ciências Humanas, Letras e Artes. A oferta piloto da disciplina ocorreu no primeiro semestre de 2006. Foram aceitas inscrições na forma de disciplina optativa (formativa) de alunos de graduação e pós-graduação de todos os cursos da UFPR e também de membros da comunidade.

\section{Dificuldades de implantação}

A grande dificuldade em seu planejamento, implantação e execução foi conciliar os interesses distintos. No caso dos docentes envolvidos, as diferentes áreas de formação e atuação se, num primeiro momento, constituíram fator positivo para a necessária amplitude de competências e olhares, dada a diversidade do tema, por outro lado, tornou necessário oestabelecimento de uma metodologia de trabalho bastante rígida e elaborada. Nesta, as responsabilidades para ministrar os conteúdos formativos gerais necessariamente tinham que ser contemporizadas pelo uso de um método em que a não especialização na área de Direito não constituísse fator inibitório.

No caso dos alunos, pela diversidade de suas origens e níveis educacionais, tornouse necessário buscar que aulas teóricas $e$ práticas tivessem um caráter mais informativo e reflexivo do que formativo em Direito, posto não ser o objetivo da disciplina. Buscou-se aliar na concepção da metodologia, que a parte teórica contivesse elementos formativos $e$ conceituais gerais e, na parte prática, focaram-se a discussão de situações reais e as possibilidades de apresentação de Projetos de Extensão à comunidade em temas ligados à Educação em Direitos Humanos. 


\section{Metodologia adotada}

A metodologia adotada consolidou-se através de: 1) aulas e palestras modulares (teoria) e 2) intervenções dos alunos e professores em temas específicos (prática). As aulas modulares, ministradas pelos diferentes docentes, versaram sobre os temas: A questão dos Direitos Humanos no Brasil e no Mundo; Direito Internacional dos Direitos Humanos; Processos Sociais, Paz e Direitos Humanos; Educação em Direitos Humanos; Organizações Internacionais e Direitos Humanos; Direito Internacional dos Refugiados e Migrantes.

Cada aula modular, baseada em um plano de aula específico e de um manual para o professor, compunha-se de: 1) material de apoio escrito, 2) apresentação de apoio em Power Point ${ }^{3}$. As palestras modulares versaram sobre as temas ligados às áreas de formação de cada docente e a reflexão sobre as questões de direitos humanos inerentes a cada tema escolhido. Foram compostas por: Direitos Humanos e Ciência, Genética e Ética, Meio Ambiente e Direitos Humanos, Cidades e Direitos Humanos, África e Direitos Humanos, Fronteiras e Direitos Humanos, Diversidade, Identidade e Cultura, Segurança Pública entre a Guerra e a Paz. Em algumas destas, houve também a manutenção da mesma estrutura: material de apoio escrito e apresentação de apoio em Power Point. Em outras, as palestras foram apenas expositivas.

Os alunos foram avaliados através de duas provas e um trabalho prático. A oferta da disciplina foi avaliada ao final por alunos e professores, conforme síntese abaixo:

\section{Materiais produzidos na disciplina e utilizados} como apoio

\section{Os materiais produzidos pelos docentes} foram disponibilizados via internet para descarga e consulta através de site próprio, já desativado, conforme Figura 2.

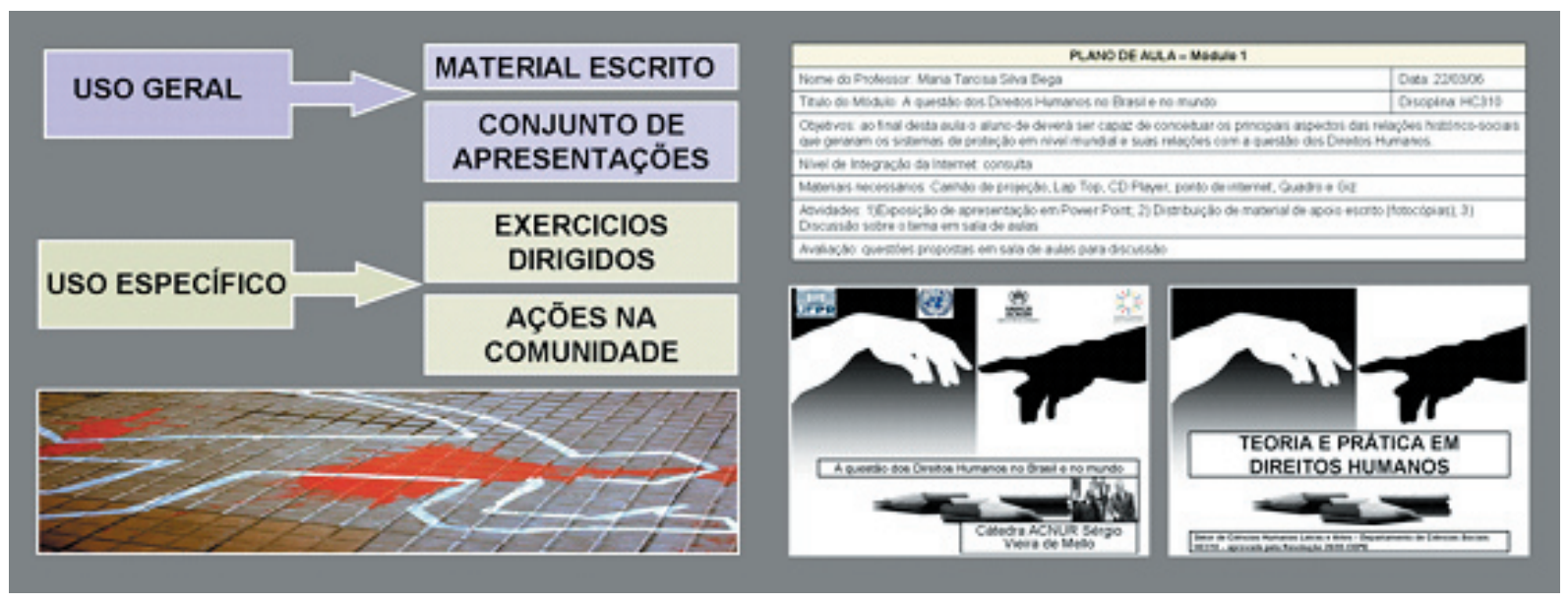

FIGURA 1 - METODOLOGIA DE ENSINO - TEORIA E PRÁTICA EM DIREITOS HUMANOS ${ }^{4}$

3 Aplicativo do MS Office, Windows, Microsoft Corporation, USA.

4 Figura 1 - Imagens Fontes: http://graomogol.zip.net/images/ e http://marxismo.files.wordpress.com/. 


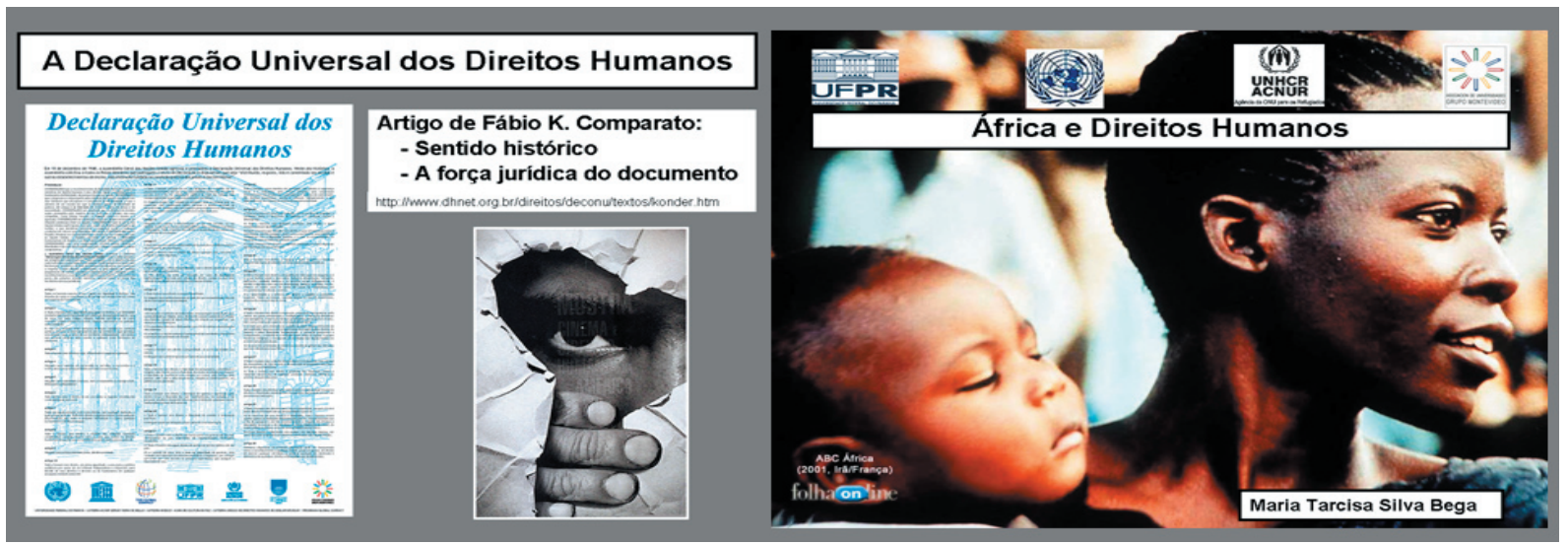

FIGURA 2 - EXEMPLOS DE MATERIAIS PRODUZIDOS 5

Outros materiais de apoio foram utilizados, tais como filmes ("O homem que virou suco", Brasil, 1981, direção de João Batista de Andrade), músicas ("Que país é este", Brasil, Legião Urbana; "Desaparciones", México, Rubem Blades, Maná; "Mi país", Uruguai, Rubem Rada), apresentações disponíveis na internet "Ilustrações_de_Curitiba.pps", Brasil,
César Lobo; "CensuradeMTV.pps", USA, MTV; "Excelente.pps", imagens, depoimentos, charges, poemas, piadas, textos, etc. A Figura 3 mostra lâminas das apresentações disponíveis na internet utilizadas como elementos de reflexão e motivação às discussões em sala e exemplos de outros materiais de apoio utilizados.

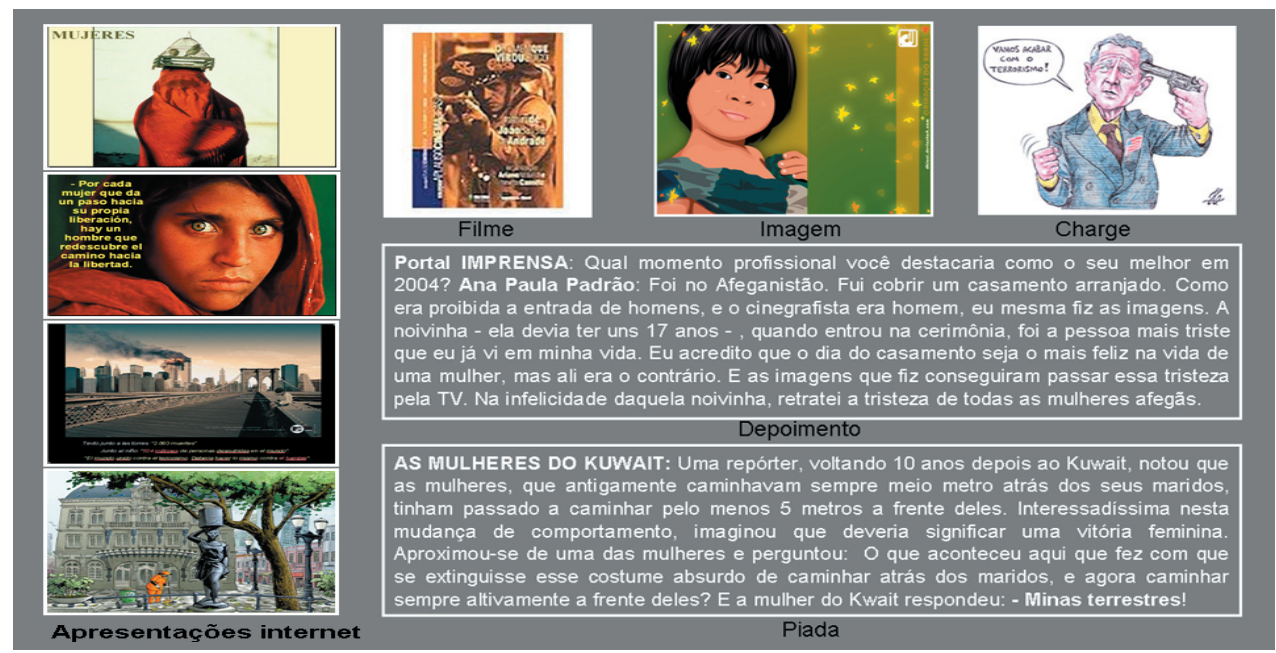

FIGURA 3 - EXEMPLOS DE MATERIAIS DE APOIO UTILIZADOS ${ }^{6}$

Figura 2 - Fonte das imagens: <http://www.sescsp.org.br/sesc/revistas_sesc/sesc/images_2006/e http://www1.folha.uol.com.br/folha/ interacao/images/>.

6 Figura 3 - Fonte das imagens: <http://i.s8.com.br/images/books/cover/img4/; http://baixaki.ig.com.br/ imagens/wpapers/ e http: //br.geocities.com/carlos.guimaraes/> . Depoimento de Ana Paula Padrão extraído de: <http://portalimprensa.uol.com.br/portal/> . 
Dados gerais da oferta-piloto

A análise das matrículas (114) realizadas inicialmente permite mapear a demanda por setores/cursos da UFPR e da comunidade em geral (disciplina isolada). Observe-se que as matrículas foram realizadas após o período regular e a demanda motivada com base apenas na divulgação eletrônica durante dois dias oferecendo a possibilidade de inscrição na disciplina no site da UFPR. Isto permite inferir que a demanda pode ser considerada como espontânea, de interesse próprio e não induzida. A Tabela 1 e o Gráfico 1 apresentam uma síntese destes números:

TABELA 1 - DISTRIBUIÇÃO DO NÚMERO DE MATRÍCULAS POR ORIGEM/CURSOS UFPR

\begin{tabular}{|c|c|c|c|}
\hline Área & $\%$ & Curso & N. ${ }^{\circ}$ matric. \\
\hline \multirow{10}{*}{$\begin{array}{l}\text { Humanas, Letras e } \\
\text { Artes }\end{array}$} & & Ciências Sociais & 29 \\
\hline & & Comunicação Social - Jornalismo & 3 \\
\hline & & Comunicação Social - Publicidade e Propaganda & 5 \\
\hline & & Filosofia & 11 \\
\hline & & Psicologia & 3 \\
\hline & & História & 1 \\
\hline & & Letras & 1 \\
\hline & & Música & 1 \\
\hline & & Turismo & 1 \\
\hline & & Administração & 1 \\
\hline Sociais Aplicadas & $3,5 \%$ & Gestão da Informação & 2 \\
\hline Jurídicas & $6,1 \%$ & Direito & 2 \\
\hline Tecnologia & $0,9 \%$ & Engenharia Elétrica & 7 \\
\hline Exatas & $0,9 \%$ & Estatística & 1 \\
\hline Terra & $1,8 \%$ & Geografia & 1 \\
\hline Saúde & $1,8 \%$ & Medicina & 2 \\
\hline Educação & $0,9 \%$ & Pedagogia & 1 \\
\hline Comunidade & $35,0 \%$ & Disciplina isolada & 40 \\
\hline
\end{tabular}

FONTE: SIE-UFPR-2006

\section{GRÁFICO 1 - DISTRIBUIÇÃO DO NÚMERO DE MATRÍCULAS POR ORIGEM/CURSOS UFPR}

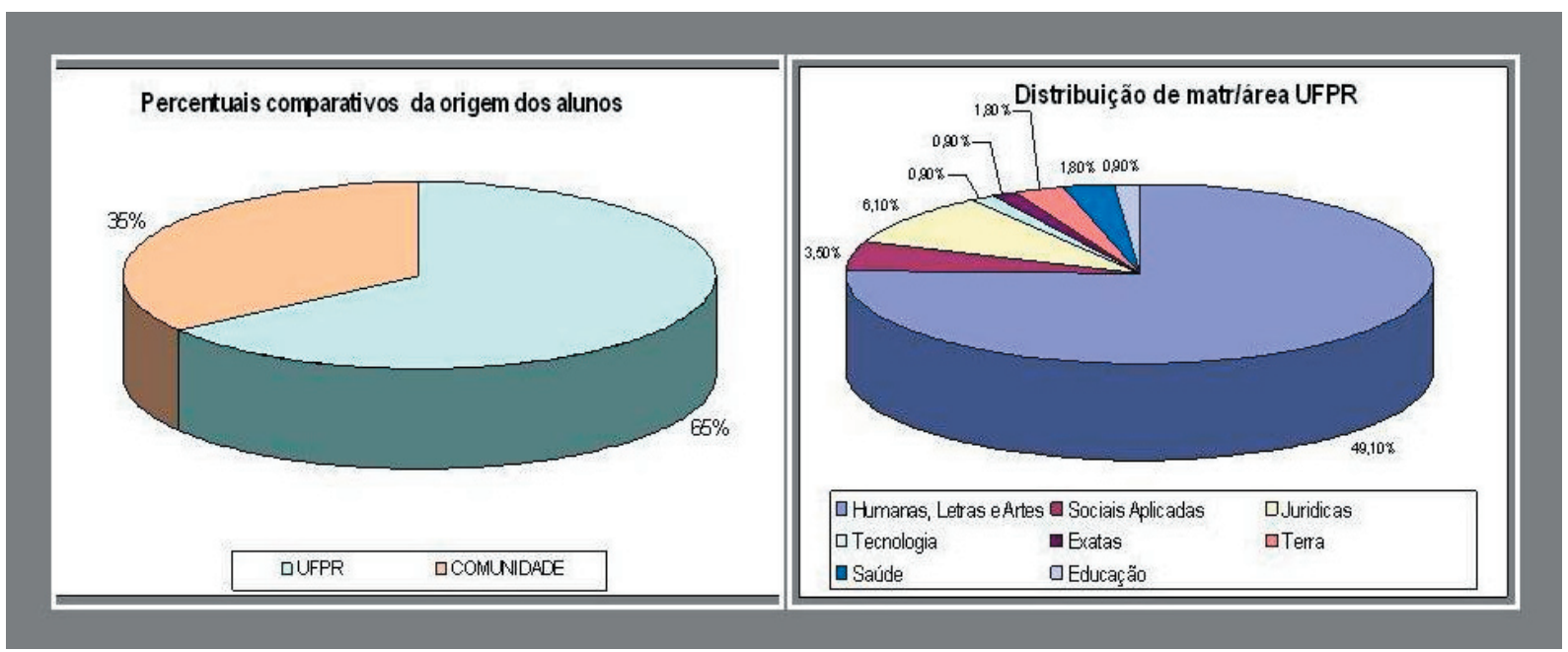

FONTE: SIE-UFPR-2006 
Analisando-se os dados relativos aos matriculados, observa-se que os maiores percentuais foram de estudantes das áreas de Ciências Humanas e Jurídicas (totalizando $55,3 \%$ dos matriculados), seguidos de um significativo percentual de $35 \%$ dos matriculados advindos da comunidade externa da UFPR. Não foi realizado um levantamento específico dos fatores motivadores destes últimos para participação na disciplina. Mas estes dados são relevantes em termos das possibilidades reais de inserção e extensão à comunidade deste tipo de trabalho educativo.

\section{Avaliação pelos estudantes}

A avaliação realizada ao final da disciplina teve alguns itens básicos avaliados. Dos questionários preenchidos, $72,7 \%$ dos que responderam se identificaram e $27,3 \%$ não se identificaram. Dentre os que se identificaram, $70,8 \%$ eram alunos da UFPR. Dos que não se identificaram, $25 \%$ assinalaram que eram alunos da UFPR. Em síntese obteve-se:

Acessibilidade à disciplina: Muito Boa (48,6\%), Aceitável (43,2\%), Ruim (8,1\%), Não qualificável $(0 \%)$;

Avaliação da metodologia: Muito Boa (51,5\%), Aceitável (41,9\%), Ruim (6,4\%), Não qualificável $(0 \%)$;

Relação professor-aluno e universidade-comunidade: foi sistematizada uma série de comentários abaixo sintetizados seguindo as linhas:

- a) Aprovativas: julgou a disciplina importante para a UFPR e comunidade; motivou os alunos na relação entre teoria e prática e no entendimento do mundo; ajudou a prestar atenção a violações que passavam despercebidas; disciplina foi interessante e abrangente, servindo a todos os cursos.

- b) Reprovativas: poderia ser maravilhosa se houvesse integração entre os professores e não realizada de forma convencional, com os alunos participando mais profundamente; difícil alinhavar os temas na primeira oferta e acreditar que as próximas seriam melhores; professores que não são da área de Ciências Humanas fogem das bases dos Direitos Humanos que deveriam nortear a disciplina.

- c) De caráter geral ou sugestivo: deu um panorama geral e permitiu se inteirar de temas que desconhecia; abriu portas para temas de pesquisa; necessário oferecer sugestões de outras disciplinas que possam complementar formação na área.

A avaliação geral da disciplina resultou comentários classificados segundo três vertentes:

- a) De caráter geral: disciplina ofereceu formação ética e moral; importante para alargar fronteiras e chamar a atenção sobre o tema; disciplina interessante e professores bons; elucidou conceitos importantes; permitiu visão internacional na área; trouxe perspectiva diferente sobre a realidade; importante para capacitar alunos como agentes de transformação; essencial para o exercício profissional; importante, pois foi possível entrar em contato com distintas áreas; o tema deveria nortear todas as relações sociais; permitiu visão mais humana sobre a sociedade.

- b) De caráter específico: aulas iniciais apenas informativas e gerais; aula sobre Direitos Humanos em diferentes contextos sociais deveria ser a primeira; destaque às aulas sobre Cidades, Meio Ambiente, Migrantes e Refugiados; fundamental para o curso de Ciências Sociais; todo acadêmico deveria ter esta formação, especialmente de Direito. 
- c) Outras: disciplina contribuiu muito pouco, pois não foi além de uma exploração básica e introdutória, esperava mais de uma disciplina da UFPR e ONU; conteúdos sem organização.

O nível de satisfação dos alunos com a disciplina foi: Muito Satisfatória $(28,1 \%)$, Satisfatória (53,1\%), Regular (9,4\%), Pouco Satisfatória (6,2\%) e Nada Satisfatória (3,1\%).

A conclusão obtida a partir do processo de avaliação da disciplina foi que pelo fato de ser a primeira oferta e de caráter piloto, os resultados foram de médio a bons $(81,2 \%$ consideram no mínimo satisfatória), com muitos pontos a serem melhorados. Entretanto, quando observada a avaliação da metodologia adotada, 93,3\% dos alunos a consideraram no mínimo aceitável. Algumas das observações anteriormente citadas, entretanto, chamaram a atenção, e evidenciam as dificuldades encontradas. Destaque-se que o desnível entre os alunos (graduação e pósgraduação) da UFPR, da comunidade (desde pessoas apenas com Nível Médio até jornalistas com larga experiência na área) foi o fator que representou maior dificuldade em termos da concepção e nível de tratamento dos conteúdos e sem dúvida causa de críticas de estudantes de níveis mais elevados. Paralelamente, observou- se a maior dificuldade no trabalho de professores que não tinham formação na área e de integração entre os trabalhos realizados. Ressalte-se que os professores envolvidos adicionaram esta atividade às outras desenvolvidas na Instituição. Outro fato que não ficou claro para alguns alunos foi o caráter básico, informativo e introdutório dessa disciplina ofertada. Estes aspectos foram relevantes para as principais dificuldades encontradas na seqüência da disciplina e críticas no final.

Propostas apresentadas pelos estudantes

A parte propositiva (componente da prática em Direitos Humanos) teve por objetivos: 1) Ensaio sobre o tema A Tortura - Aportes interdisciplinares para a reflexão e prevenção, e 2) Produção de material didático para cursos de extensão sobre Direitos Humanos junto às Escolas Públicas do Estado do Paraná, sobre os temas: (a) Educação Inclusiva; (b) Meio Ambiente; (c) Gênero; (d) Raça e Etnia; (e) Cultura Urbana; (f) Violência e Segurança, conforme tabelas 2 e 3 , a seguir.

Alguns trabalhos de produção de materiais podem também ser destacados, todos com imediata possibilidade de aplicação na forma de extensão universitária.

\section{Temas tratados Autores}

Tortura em trotes; tortura no Brasil; tortura feminina

$\mathrm{O}$ ato de atormentar através dos tempos

Tortura e a responsabilidade jurídico-social
Anna Claudia Oliveira; Erica F. da Silva; Fernanda Marchesi; Marisa A. da Fonseca Rafael Scalfi

Clarice Azvedo; Eni Sanchez; Felipe Folly; Raquel Sanchez 


\begin{tabular}{|c|c|c|}
\hline Título/Autores & Tema principal & Aplicação \\
\hline $\begin{array}{l}\text { "Cada gota conta" } \\
\text { Paula Santos Lima }\end{array}$ & A questão da água & $\begin{array}{l}\text { Cartilha sobre o uso racional da água visando a divul- } \\
\text { gação e a conscientização da população. }\end{array}$ \\
\hline $\begin{array}{l}\text { "Corpo e controle: o } \\
\text { outro lado da beleza" }\end{array}$ & A questão de gênero & $\begin{array}{l}\text { Discussão do processo de construção histórica e social } \\
\text { da feminilidade e masculindade como fumdamental na } \\
\text { cultura da modernidade. }\end{array}$ \\
\hline $\begin{array}{l}\text { "Educação inclusiva } \\
\text { em Direitos Humanos" } \\
\text { Leandra Fontana }\end{array}$ & $\begin{array}{l}\text { Educação em } \\
\text { Direitos Humanos }\end{array}$ & $\begin{array}{l}\text { Refletir sobre a perceção que os/as professores/as têm } \\
\text { sobre o cotidiano escolar para a implementação e } \\
\text { consolidação de uma prática educativa e insluvia em } \\
\text { Direitos Humanos }\end{array}$ \\
\hline $\begin{array}{l}\text { "Proposta de produção } \\
\text { de material didático" } \\
\text { Débora Scottini }\end{array}$ & $\begin{array}{l}\text { Educação em } \\
\text { Direitos Humanos }\end{array}$ & $\begin{array}{l}\text { Educação, formação e capacitação de recursos hu- } \\
\text { manos visando a consolidação de uma rede de ci- } \\
\text { dadãos conscientizados das políticas públicas voltadas } \\
\text { para os Direitos Humanos. }\end{array}$ \\
\hline $\begin{array}{l}\text { "Direitos humanos e a } \\
\text { violência: uma } \\
\text { proposta para a rede } \\
\text { pública de ensino" } \\
\text { K. Mendes e L. Cristo }\end{array}$ & $\begin{array}{l}\text { Educação em } \\
\text { Direitos Humanos }\end{array}$ & $\begin{array}{l}\text { Material didático para um curso de extensão sobre } \\
\text { Direitos Humanos que enfatize o subtema Violência } \\
\text { e Segurança, por meio de aulas com a utilização que } \\
\text { fazem parte do universo dessa faixa etária. }\end{array}$ \\
\hline
\end{tabular}

\section{A extensão da proposta}

Com base na experiência-piloto realizada na disciplina é possível situar as possibilidades de extensão da proposta de um trabalho sistemático em educação em Direitos
Humanos, em diferentes tipos de ações, tomando por base os resultados obtidos principalmente em termos do nível de interesse e participação. Neste sentido, algumas das ações possíveis a partir da universidade podem ser de diversas amplitudes e inter-relações, como mostradas na Figura 4.

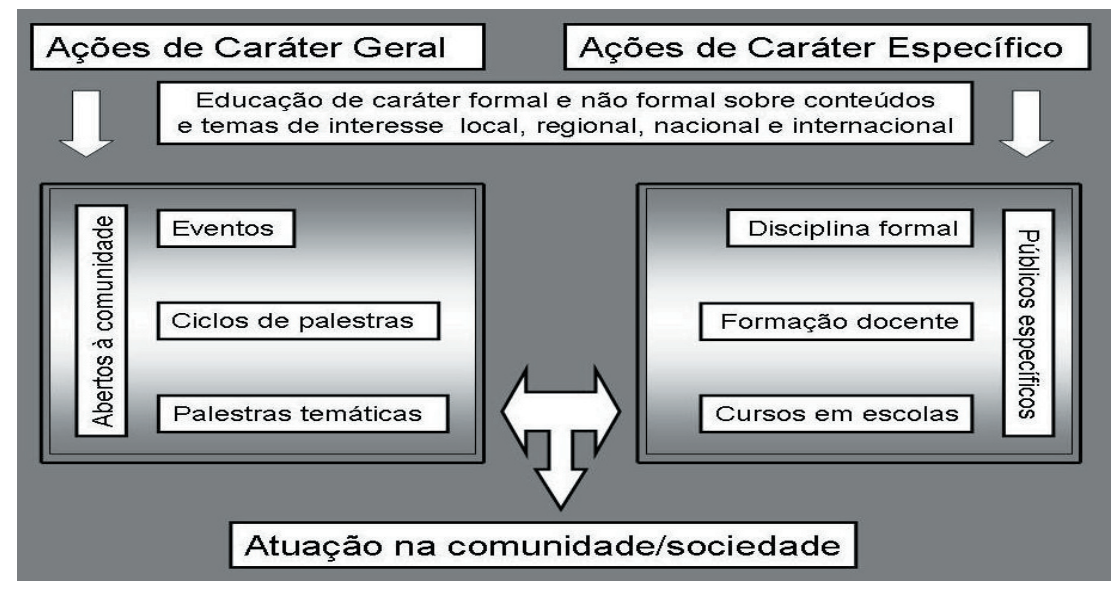

FIGURA 4 - ALGUMAS AÇÕES POSSÍVEIS A PARTIR DA UNIVERSIDADE 


\section{Ações de caráter geral}

Dentre as ações possíveis de caráter geral e sempre abertas a toda a comunidade, indicase a realização de eventos, de ciclo de palestras, $e$ de palestras temáticas como instrumentos eficazes para a sensibilização de parcelas da sociedade e que, ao mesmo tempo, possibilitem a divulgação do trabalho através da mídia.

Os eventos sobre temas gerais, regionais e locais, permitem focar a discussão destes, aprofundamento em distintos aspectos e encaminhamentos de possíveis ações multiplicadoras, educativas e corretivas, como conseqüência. A presença de pessoas de renome nas matérias tratadas, de maneira geral, desperta um grande interesse e participação. Os eventos, em geral anuais ou semestrais, são instrumentos que permitem a identificação de grupos com interesse nas diversas possíveis áreas de trabalho junto à comunidade.

As atividades denominadas genericamente ciclos de palestras (mesas redondas, apresentações individuais, oficinas, etc.) permitem uma discussão mais delimitada $e$ aprofundada de temas de especial interesse e, se distribuídos no tempo (mensais, semanais), representam uma especial oportunidade para ações de caráter mais pontual. Por exemplo, palestras sobre a condição carcerária no Brasil, podem gerar ações específicas em cada comunidade para a melhoria da condição carcerária regional e local, catalisando ações como visita a presídios, organização de bibliotecas em presídios, estabelecimento de sistemática de auxílio jurídico a presos, apoio às famílias, busca pela adequação às condições de gênero nos presídios femininos, combate à violência em delegacias e instituições carcerárias em geral, etc.

As palestras temáticas podem ter duas principais características: 1) sobre um assunto específico, a partir da competência acadêmica ou profissional de quem a profere $e$ destinadas para um público interessado; 2) com um objetivo específico, a partir do público a quem se destina. Neste caso, o tema tratado deve ser de interesse e motivador para cada público, que pode ser composto de empresários, membros de clubes de serviço, estudantes ou docentes de escolas públicas, sindicatos, comunidades de pescadores, ribeirinhas, etc.

Como decorrência destas ações, espera-se que as pessoas participantes possam atuar na sociedade pela mudança, emoção, correção de desvios e pela construção de uma nova realidade.

\section{Ações de caráter específico}

As possíveis ações pedagógicas de caráter formal podem ocorrer através de inúmeras maneiras: 1) Disciplina formal destinada a estudantes universitários e à comunidade; 2) Cursos de formação de professores da Educação Básica; 3) Cursos aos alunos em escolas da Educação Básica. Certamente outras decorrentes são possíveis, como cursos para gestores públicos, agentes penitenciários, membros de Conselhos (tutelares, de segurança etc), policiais, jornalistas, etc.

Guardadas as devidas proporções, propõe-se o estabelecimento de uma metodologia de trabalho que permita, a partir das observações e conclusões da oferta-piloto realizada pela UFPR, trabalhar sobre conteúdos que habilitem o acesso instrumental ao conjunto de conceitos básicos sobre temas de Direitos Humanos e, ao mesmo tempo, à contribuição dos grupos participantes na construção de propostas, projetos, ações específicas, grupos de trabalho, etc.

A descrição realizada no item 2 da implantação, metodologia adotada, materiais produzidos e de apoio utilizados na disciplina Teoria e Prática em Direitos Humanos, podem servir de base para trabalhos semelhantes em instituições universitárias, mas tendo a clareza que há inúmeras outras possibilidades diferentes de formas de trabalho. No caso da UFPR, pela participação de docentes de diferentes áreas de formação, o trabalho realizado mostrou-se 
eficaz, apesar das dificuldades evidenciadas. Caso o grupo de docentes tenha formação específica na área, ou que os alunos sejam de cursos afins à área, certamente é possível uma dimensão muito mais aprofundada sobre os aspectos teóricos e documentais, principalmente se o nível de trabalho for o de pós-graduação. $\mathrm{O}$ desafio permanece, entretanto, se o público for da comunidade não acadêmica, dada sua heterogeneidade de formação original.

Os cursos para formação de professores podem ser, de certa maneira, considerados como muito próximos à experiência-piloto da UFPR, pela presença de professores de diferentes áreas, participando como alunos. Nesse sentido, a formação deverá privilegiar conteúdos gerais, informadores e formadores, de forma a propiciar a aplicabilidade do estudado a cada área específica. Um curso de formação de professores em Direitos Humanos somente terá êxito se cada educando (professor) conseguir estabelecer ligação entre os temas tratados com suas áreas de atuação, de forma a construir seus próprios caminhos para a execução de iniciativas que possibilitem uma conscientização $e$ conseqüentes ações em relação aos seus próprios alunos, à sua atividade docente, à sua escola, e à sua comunidade. Tome-se como exemplo um professor de Física. A discussão dos aspectos do desrespeito aos direitos humanos ocasionados pela deflagração de conflitos, necessariamente deverá possibilitar a ele a descoberta de que a ciência Física evoluiu (conceitual e tecno- logicamente) em função de guerras; que os cientistas sempre estiveram atrelados a esforços bélicos de governos desde a antiguidade. Poderse-á também tratar da questão de gênero pela ênfase do que na Física ocorre pela quase ausência de mulheres nela atuando, as razões, os preconceitos, as soluções, etc.

Este tipo de curso deveria ser ofertado sempre que se trabalhe com formação continuada de docentes, devendo a questão de carga horária ser avaliada caso a caso.

Os cursos em escolas (tomados como exemplo e passíveis de serem destinados a quaisquer outros grupos sociais) devem ser curtos, de cinco a dez horas, sendo cada aula de no máximo uma hora. Nesses, a lógica formativa, reflexiva e catalisadora de ações, deve estar estreitamente aliada à realidade local e aos problemas sociais locais e regionais. Deve ser dada grande ênfase à intervenção dos estudantes. A sistematização destas intervenções deve ser o ponto central, pois expressaria o que de mais importante atingiria os estudantes, de maneira que a escola, pais e comunidade possam avaliar exatamente quais os problemas que mais afligem o grupo-alvo (alunos). Por exemplo, pode-se utilizar uma ficha-síntese de cada tema e de cada grupo, de maneira que, a partir delas, se estabeleçam caminhos para a minimização e solução de problemas apontados. A Figura 5 mostra como este tipo de ficha pode ser construída e organizada.

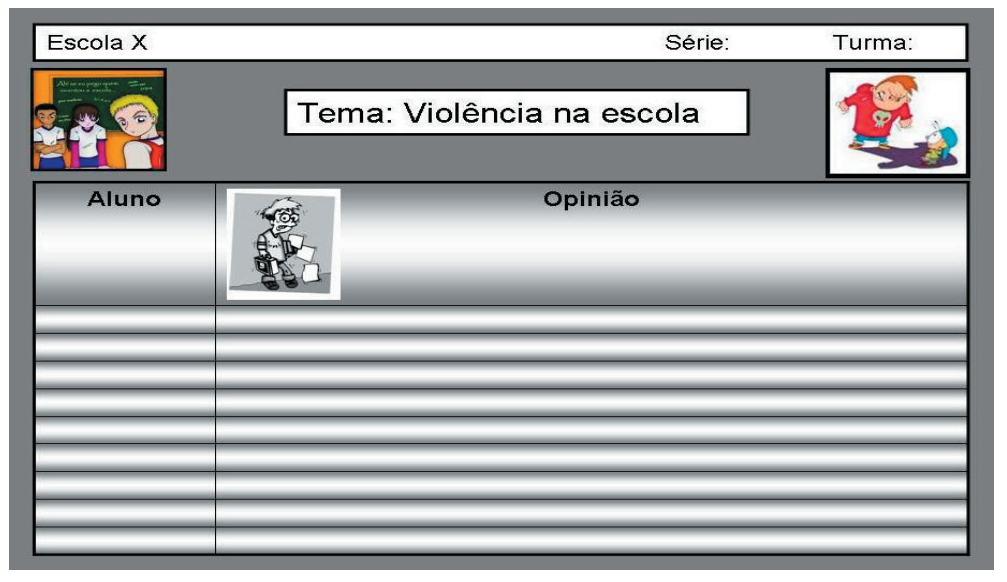

FIGURA 5 - EXEMPLO DE FICHA-SÍNTESE - CURSOS EM ESCOLAS - TEMAS ESPECÍFICOS 


\section{Conclusões}

Conforme evidenciado, é possível a proposição e consolidação de ações de caráter educativo em Direitos Humanos a partir da universidade. A experiência realizada na UFPR pela oferta-piloto da disciplina, apesar das dificuldades encontradas, foi avaliada positivamente. A metodologia de trabalho utilizada abre possibilidades de sua extensão a outros tipos de oferta. Paralelamente, permite a discussão que este tipo de trabalho pode ser efetivamente realizado de maneira sistemática e com muito maior amplitude, pelo evidente interesse sobre o assunto. $\mathrm{O}$ que se busca, a partir desta experiência, é assinalar que as possibilidades são inúmeras e de largo espectro, bastando a vontade de construí-las. Os reflexos para a comunidade e a sociedade somente poderão ser mensurados a partir do momento em que a consciência cidadã permitisse reescrever o parágrafo destacado do texto da revista Veja. Desta forma, se poderia talvez encontrar:

Na pesquisa encomendada por VEJA, chama atenção o fato de $51 \%$ dos espectadores desaprovarem a tortura como um meio de extrair confissões de criminosos. É uma maioria pequena - $47 \%$ aprovam esse método desumano -, mas que aponta no sentido da civilização. É inaceitável esta proporção de brasileiros adeptos da tortura policial tendo em vista os conceitos de cidadania vigentes em nossa sociedade.

Melhor seria se fosse esse o texto da revista:
Na pesquisa encomendada por VEJA, chama atenção o fato de a quase totalidade dos espectadores (91\%) desaprovarem a tortura como um meio de extrair confissões de criminosos. É uma pequena parcela que aprova esse método desumano - o que aponta que a civilização já é uma realidade, mas que devemos nos manter alerta. Mesmo pequena, é inaceitável esta proporção de brasileiros adeptos da tortura policial tendo em vista os conceitos de cidadania vigentes em nossa sociedade.

\section{Declaração Universal dos Direitos Humanos - Artigo $26^{7}$}

1. Toda a pessoa tem direito à educação. A educação deve ser gratuita, pelo menos a correspondente ao ensino elementar fundamental. O ensino elementar é obrigatório. O ensino técnico e profissional dever ser generalizado; o acesso aos estudos superiores deve estar aberto a todos em plena igualdade, em função do seu mérito.

2. A educação deve visar à plena expansão da personalidade humana e ao reforço dos direitos do Homem e das liberdades fundamentais $e$ deve favorecer a compreensão, a tolerância e a amizade entre todas as nações e todos os grupos raciais ou religiosos, bem como $\mathrm{o}$ desenvolvimento das atividades das Nações Unidas para a manutenção da paz.

3. Aos pais pertence a prioridade do direito de escolher o gênero de educação a dar aos filhos.

Disponível em: <http://www.unhchr.ch/udhr/lang/por.htm>. 


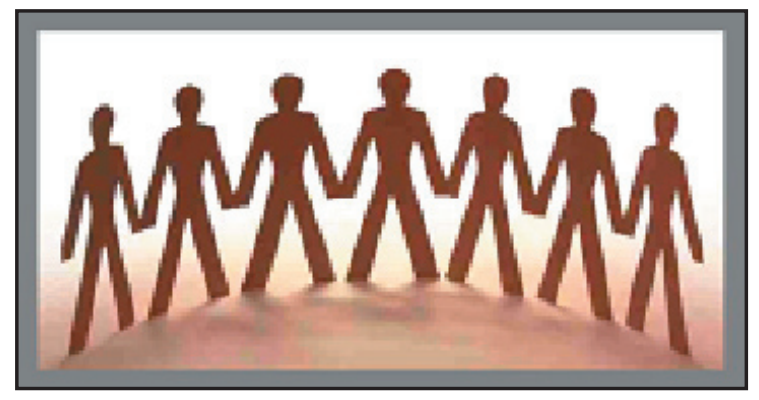

FONTE: <http://www.ddh.mre.gov.br/imagens/>.

\section{REFERÊNCIAS}

BENEVIDES, M. V. Educação em Direitos Humanos: de que se trata? In: SEMINÁRIO DE EDUCAÇÃO EM DIREITOS HUMANOS, São Paulo, 18/02/2000. Disponível em: <http://www.hottopos.com/convenit6/victoria.htm>. Acesso em: 12/11/2007.
CARNEIRO, M. A realidade, só a realidade. Revista Veja, n. 2030, out. 2007. Disponível em: <http://veja.abril.com.br/ 171007/p_080.shtml>. Acesso em: 12/11/2007.

Texto recebido em 15 ago. 2007 Texto aprovado em 25 mar. 2008 